Article

\title{
Comprehensive Spray Characteristics of Water in Port Fuel Injection Injector
}

\author{
Jeonghyun Park ${ }^{1}$, Kyung-Hwan Lee ${ }^{2}$ and Suhan Park ${ }^{3, *}$ \\ 1 Department of Mechanical Engineering, Graduate School of Chonnam National University, 77 Yongbong-ro, \\ Buk-gu, Gwangju 61186, Korea; wsed33@naver.com \\ 2 School of Mechanical and Aerospace Engineering, Sunchon National University, 255 Jungang-ro, \\ Suncheon-si, Jeonnam 57922, Korea; khlee@sunchon.ac.kr \\ 3 School of Mechanical Engineering, Chonnam National University, 77 Yongbong-ro, Buk-gu, \\ Gwangju 61186, Korea \\ * Correspondence: suhanpark@jnu.ac.kr; Tel.: +82-62-530-1674
}

Received: 18 December 2019; Accepted: 9 January 2020; Published: 13 January 2020

\begin{abstract}
The objective of this study was to compare the injection and spray characteristics of water with n-heptane using a port fuel injection (PFI) system. In this study, the injection pressure was changed to $0.3-0.9 \mathrm{Mpa}$ and the energizing duration was changed to $0.5-4 \mathrm{~ms}$. To investigate spray characteristics, the injection quantities of n-heptane and water were measured. Macroscopic spray characteristics were determined through spray visualization. The Sauter mean diameter (SMD) and velocity of spray droplets were measured with a phase Doppler anemometry (PDA) experiment. Spray tip penetration, spray angle, SMD of droplets, and spray droplet velocity were compared. As the injection pressure increased, the injection quantity and the droplets velocity increased. However, the spray tip penetration, SMD of the droplet, and the spray angle decreased. The increase in energizing duration led to an increase in the injection quantity without affecting other spray characteristics. The higher density of water also increased injection quantity, resulting in a decrease in spray tip penetration and increases of SMD and velocity of spray droplets due to high viscosity and surface tension of water.
\end{abstract}

Keywords: spray; port fuel injection (PFI) system; water injection; n-heptane; droplet size; droplet velocity

\section{Introduction}

Declining oil reserves and increasingly stringent emissions regulations call for new solutions for internal combustion engine manufacturers. Therefore, manufacturers have produced engines by adopting alternative fuel applications, miniaturization, direct injection, and overcharging for conventional engines. The compacting and overcharging of the engine are expected to improve the overall engine efficiency by about $16 \%$, with effects such as pumping loss, weight loss, and reduced friction loss [1]. However, overcharging is caused by the problem of increasing pressure and temperature in the cylinder due to abnormal combustion and ignition instability, called knocking. To solve this problem, the spark timing can be adjusted to lower the peak pressure and temperature. However, excessive use of this method is limited because it leads to a significant reduction in combustion stability and fuel economy, which adversely affects engine efficiency and power. Therefore, researchers have tried to solve the problem using a variety of methods, including cooling exhaust gas recirculation (EGR), rich mixture, and fuel with a high octane number [1-5].

Among various methods for solving such problem, water injection with high anti-knock characteristics has attracted attention recently. Water injection enables high compression ratios 
and supercharging. It also reduces engine fuel consumption due to the high specific heat of water. In addition, due to the charge cooling effect, $\mathrm{NO}_{\mathrm{x}}$ is significantly reduced by increasing the heat capacity of the mixer and decreasing the adiabatic flame temperature [6]. When applying water injection, the rate of reduction in flame propagation speed is greater than that of applying EGR. Therefore, water injection is more beneficial to the reduction of $\mathrm{NO}_{\mathrm{x}}$ emissions than EGR application [7]. Many studies confirmed that water injection does not have a direct effect on $\mathrm{CO}$ or $\mathrm{CO}_{2}$ emission, although it is expected to reduce $\mathrm{CO}_{2}$ due to increased fuel efficiency. However, combustion at low temperatures due to water injection has a disadvantage of increasing hydrocarbons (HC) [8-13].

Water injection engines began in the early 1930s and have been studied for a long time in various ways. Water injection engines can be divided according to water injection location $[14,15]$. Water injection can be divided in two main ways: Injection water or water emulsified fuel with an engine. The water emulsified fuel method has the advantage of low water consumption, but it is necessary to replace the fuel system and the high-pressure pump in order to solve the corrosion and freezing problems. Thus, the cost increases due to a completely new pressure system. It can also be a problem for starting the engine, so the water must be removed with pure gasoline. Consequently, a method involving the injection of water into the intake port has been mainly used for charge cooling effect among various water injection positions recently. In a gasoline direct injection (GDI), the engine that directly injects fuel into the cylinder, a port fuel injection (PFI) system, is added to inject water into the intake port. Using the PFI system, water is injected into the intake port at a relatively low pressure of 0.5-0.7 MPa. In addition, intake port water injection has advantages of being a simple and economical injection system with relatively easy handling of water corrosion and freezing problem $[2,16]$. However, it has a disadvantage of increasing water consumption [17].

For these reasons, experimental and analytical studies of water injection have been conducted around the world. Berni et al. conducted analytical studies on intake port water injection in the GDI engine, confirming an increase in indicated power and $17 \%$ reduction in fuel consumption [7]. Worm et al. examined the injection quantity and efficiency of water through port water injection experiments on spark ignition (SI) engines. It was confirmed that the maximum average effective pressure increased by $5 \%$ and that the thermal efficiency increased by $34 \%$ [16]. Younkins et al. found that $\mathrm{NO}_{\mathrm{x}}$ emissions are decreased by $87 \%$ by adding water injection to direct injection (DI) engines that supply hydrogen [18]. Hountalas experimentally determined the effect of $\mathrm{NO}_{\mathrm{x}}$ reduction through water emulsion in place of EGR, which increases fuel consumption and generates soot in diesel engines. In addition, water emulsion showed higher $\mathrm{NO}_{x}$ reduction than intake port water injection [19]. Tornatore et al. confirmed the stable possibility of lean combustion due to the improvement of anti-knock and fuel efficiency when water injection is applied [20]. Many researchers are studying water spray and evaluating the possibilities.

In gasoline engines, the PFI system has been studied for a long time and has reached a mature stage. However, spray characteristics of the PFI system have not been studied in recent years due to changes in GDI engines. Bellato et al. predicted spray mixture formation of PFI systems through analysis and verified it through experiments [21]. Anand et al. studied the distribution of spray and droplet size using a multi-hole PFI system with gasoline-ethanol mixed fuel [22]. Despite differences in viscosity, gasoline and ethanol showed similar characteristics in terms of spray progression and droplet size. Zhu et al. compared emission characteristics of exhaust gases using GDI and PFI systems. Although GDI systems have the advantage of low fuel consumption, they have the disadvantage of emitting more total hydrocarbon (THC), particulate matter (PM), and particle number (PN) [23]. Bhagat et al. investigated the spray characteristics of a multi-hole injector using experimental and analytical methods for natural intake and supercharge engine conditions [24]. They found that the higher the temperature, the lower the STP due to the collapse of spray plume. In addition, when the water injection timing was 90 before top dead center (BTDC), it reduced the formation of wall wetting on the piston surface, cylinder head, and cylinder wall, and caused vaporization better than 60 BTDC. 
Although it is optimal to apply water injection to PFI system, there is a lack of research analyzing the spray characteristics of water spray using PFI systems.

As interest in water injection has increased recently, various studies on water injection have been actively conducted in different countries. Many studies on PFI systems have been conducted during recent years. The water injection supplies water to the intake port to form a water-air mixture, which is then subjected to a more difficult and complicated process in which gasoline is directly injected into the combustion chamber and combusted. In addition, water is expected to have significantly different physical properties from gasoline, resulting in different injection and spray characteristics. Accordingly, it is essential to understand not only spray characteristics of fuel, but also spray characteristics of water [25]. However, most of water injection research studies focused on the combustion process and exhaust gas research, while research on injection and spray characteristics of the water applied to the PFI system was insufficient.

Therefore, the purpose of this study was to propose suitable injection conditions by comparing fuel and water injection and spray characteristics for water injection using a PFI system in a gasoline engine. Fuel was replaced with n-heptane known to have similar physical properties to those of gasoline. Experiments were performed with varying injection pressure and energizing duration. To determine macroscopic spray characteristics, spray tip penetration and spray cone angle were measured by macroscopic spray visualization. The size and velocity characteristics of spray droplets of $n$-heptane and water in PFI systems were compared using a phase doppler anemometry (PDA) system.

\section{Experimental Setup and Procedure}

The experimental apparatus for visualizing the macroscopic spray flow of water and n-heptane injected from PFI systems is shown in Figure 1a. The visualization test apparatus was divided into fuel supply unit, signal control unit, and image acquisition unit. Visualization was performed by installing an injector in a constant volume chamber. The constant volume chamber had a volume of $2.36 \mathrm{~L}$ with a $100-\mathrm{mm}$ optical window. The injection pressure of the fuel was adjusted to $0.3-0.9 \mathrm{MPa}$ by pressurizing the pressurized auxiliary tank containing fuel with nitrogen. The injector was controlled using a LabVIEW program, a Compact RIO controller (NI, cRIO-9030), differential digital input (NI, 9411), and an injector controller (NI, 9751) from the National Instruments. In addition, the spray of water and n-heptane was visualized with a Mie -scattering method. A high-speed camera (FASTCAM, Mini AX100), a lens (SIGMA, 105 mm f/1:2.8 DG MACRO HSM) and a 250-W metal halide lamp (Lighterrace, MID-25FC) were used for spray image acquisition. A signal generator (Berkeley Nucleonics Corp. model 575) was used to synchronize and control the signal between the injector and the camera. The experiment was conducted under the condition of fuel temperature and ambient temperature of $20^{\circ} \mathrm{C}$ and ambient pressure of $1 \mathrm{~atm}$.

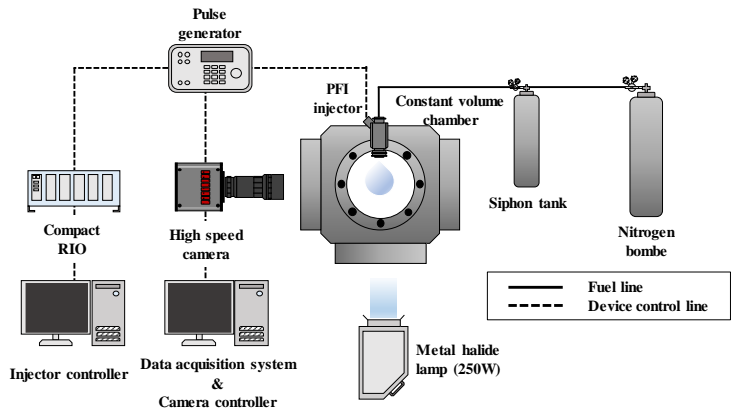

(a)

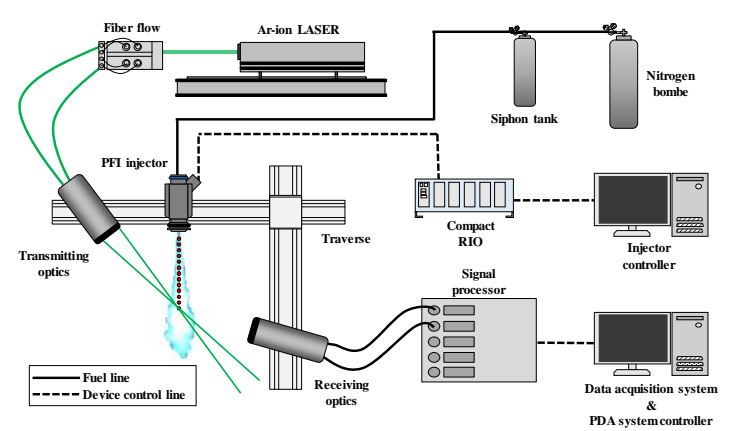

(b)

Figure 1. Schematic diagram of (a) spray visualization system (b) droplet size velocity measurement system (PDA system). 
Raw spray images obtained through macroscopic spray visualization experiments were post-processed for quantitative data. The image post-processing process was performed using a program based on MATLAB with the following sequence: Background removal, black and white, binarization, and noise reduction. Using the post-processed image, it was possible to distinguish between areas where sprays were present and those that were not, and to quantify various spray characteristics. Because the PFI system operated at lower injection pressures than the injector with direct injection, the droplets of the spray were relatively large and clearly distinguishable from the background. Therefore, the threshold used for image processing in this study was used as a fixed value. For quantitative analysis of macro spray visualization characteristics of the PFI system, spray tip penetration and injection cone angle were defined, as shown in Figure 2. The spray tip penetration was defined as the maximum distance from the injector tip to the spray edge. The spray cone angle was defined as the angle between the center of the injector tip and end points of the spray.

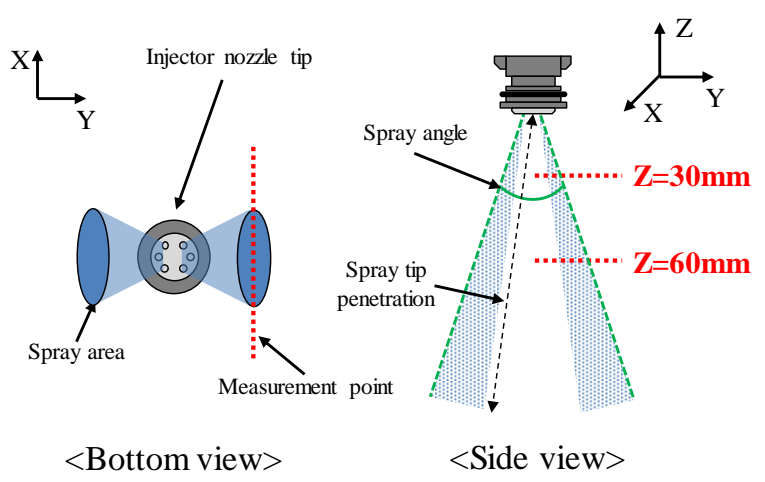

Figure 2. Definition of spray visualization experiment terminology and PDA experimental measurement area.

Figure $1 b$ is a PDA device for measuring the size and velocity of spray droplets. PDA tester is also composed of a fuel supply unit, a signal control unit, and a measuring unit. The PDA used in this study was a 1D-PDA system that was capable of measuring the droplet size and the vertical velocity. An Ar-ion laser with a wavelength of $514.5 \mathrm{~nm}$ was used as the light source. The collection angle was set to $35^{\circ}$ and the focal length was $400 \mathrm{~mm}$ according to the fuel used in this study. Measured data were converted into data through a signal processor and stored in a computer. Figure 2 shows a schematic of the measurement area for the PDA experiment. To analyze the size and velocity of spray droplets, the PDA experiment was carried out by selecting a point $30 \mathrm{~mm}$ or $60 \mathrm{~mm}$ away from the injector tip where the spray was considered to be fully developed downstream. Twelve holes were divided into two groups of six and sprayed. It was assumed that two spray plumes were symmetrical. Therefore, spray droplets sprayed from one spray plume (from six holes) were analyzed by PDA experiment. In addition, the experiment was performed by selecting $Y=8 \mathrm{~mm}$ in $Z=30 \mathrm{~mm}$ and $Y=14 \mathrm{~mm}$ in $\mathrm{Z}=60 \mathrm{~mm}$, which was considered to be the spray center because the spray was not widely spread due to the PFI system characteristics.

$$
D_{32}=\frac{\sum_{i=1}^{N} D_{i}^{3}}{\sum_{i=1}^{N} D_{i}^{2}}
$$

In this study, $D_{32}$ (Sauter mean diameter, SMD) was used to examine the size of spray droplets through PDPA experiment. D10 (arithmetic mean diameter, AMD) was the linear average value of all drops in the spray. $D_{32}$ (SMD) was the diameter of the drop whose ratio of volume to surface area was the same as that of the entire spray [26]. Unlike AMD, which calculates the size of a droplet as an arithmetic mean, SMD can be calculated by the volume/surface of the droplet, as shown in Equation (1). In fluid dynamics, $D_{32}$ is commonly used to define the particle size by weighting large droplets in the distribution of $D_{32}$ droplets. 
In this study, n-heptane was used as a substitute for gasoline fuel to compare injection and spray characteristics of gasoline and water of PFI systems. Although n-heptane had similar physical properties to those of gasoline, it was considered to be more suitable for analyzing injection and spray characteristics because of its relatively uniform spraying as a single component fuel. In addition, n-heptane has been recommended as a fuel for spray experiments in gasoline spray measurement evaluation criteria [27]. The physical properties of gasoline, n-heptane, and water are shown in Table 1. It can be seen that physical properties such as density, viscosity, and surface tension of water are all greater than those of n-heptane.

Table 1. Properties of test fuels.

\begin{tabular}{cccc}
\hline & Gasoline & N-Heptane & Water \\
\hline Molecular formular & - & $\mathrm{n}-\mathrm{C}_{7} \mathrm{H}_{16}$ & $\mathrm{H}_{2} \mathrm{O}$ \\
Molecular weight & - & 100.2 & 18.02 \\
Density $\left(\mathrm{kg} / \mathrm{m}^{3}\right)$ & 746 & 682 & 1000 \\
Viscosity $(\mathrm{mPa} . \mathrm{s})$ & 0.6 & 0.386 & 0.890 \\
Surface tension $(\mathrm{mN} / \mathrm{m})$ & 21.3 & 20.53 & 71.99 \\
Lower heat value $(\mathrm{MJ} / \mathrm{kg})$ & 44.1 & 44.566 & - \\
Latent heat $(\mathrm{kJ} / \mathrm{kg})$ & $310-340$ & 316 & 333.55 \\
\hline
\end{tabular}

Table 2 shows experimental conditions used in this study. In the present study, 12-hole PFI systems were used. Water, and n-heptane were used to compare the injection and spray characteristics. In the experiment for measuring the injection quantity, the injection pressure was increased to $0.3 \mathrm{MPa}$, $0.5 \mathrm{MPa}, 0.7 \mathrm{MPa}$, and $0.9 \mathrm{MPa}$ and the energizing duration was increased from $0.5 \mathrm{~ms}$ to $4 \mathrm{~ms}$ in 0.5-ms increments.

Table 2. Experimental conditions.

\begin{tabular}{|c|c|c|c|}
\hline \multicolumn{2}{|c|}{ Type of Experiment } & Conditions & Value \\
\hline \multicolumn{2}{|c|}{ Common } & $\begin{array}{l}\text { Injector } \\
\text { Fuel }\end{array}$ & $\begin{array}{l}\text { 12-hole PFI system } \\
\text { n-heptane, Water }\end{array}$ \\
\hline \multicolumn{2}{|c|}{ Injection quantity } & $\begin{array}{l}P_{\text {inj }}(\mathrm{MPa}) \\
\mathrm{t}_{\text {eng }}(\mathrm{ms})\end{array}$ & $\begin{array}{c}0.3,0.5,0.7,0.9 \\
0.5-4 \text { (increasing by } 0.5 \mathrm{~ms} \text { ) }\end{array}$ \\
\hline Spray and PDA & $\begin{array}{l}\text { Effect of } t_{e n g} \\
\text { Effect of } P_{\text {inj }}\end{array}$ & $\begin{array}{c}P_{\text {inj }}(\mathrm{MPa}) \\
t_{\text {eng }}(\mathrm{ms}) \\
\mathrm{P}_{\text {inj }}(\mathrm{MPa}) \\
\mathrm{t}_{\text {eng }}(\mathrm{ms})\end{array}$ & $\begin{array}{c}0.5 \\
1,2,3,4 \\
0.3,0.5,0.7,0.9 \\
2.795\end{array}$ \\
\hline
\end{tabular}

The spray pressure was fixed at $0.5 \mathrm{MPa}$ and the energizing duration was increased from $1 \mathrm{~ms}$ to $4 \mathrm{~ms}$ in 1-ms increments in order to examine the characteristics according to the change in energizing duration between spray visualization and PDA experiments. In order to see the effect of the injection pressure, the experiment was conducted with the injection pressure changed to $0.3 \mathrm{MPa}, 0.5 \mathrm{MPa}$, $0.7 \mathrm{MPa}, 0.9 \mathrm{MPa}$, while the energization period was fixed at $2.795 \mathrm{~ms}$.

The schematic of the PFI system used in this study and the image of the hole are shown in Figure 3. A 12-hole gasoline injector for port fuel injection engines was used. The injector holes were divided into two groups of six semicircular shapes, forming two spray plume groups with a spray angle of about $20^{\circ}$. The injector nozzle tip was photographed using SEM. The average diameter of the injector hole was about $138 \mu \mathrm{m}$. 


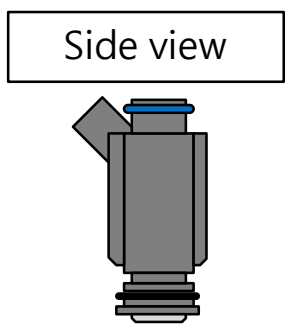

(a)

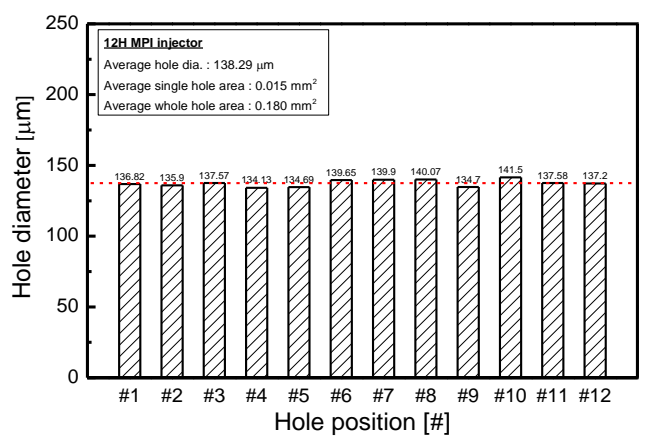

(b)

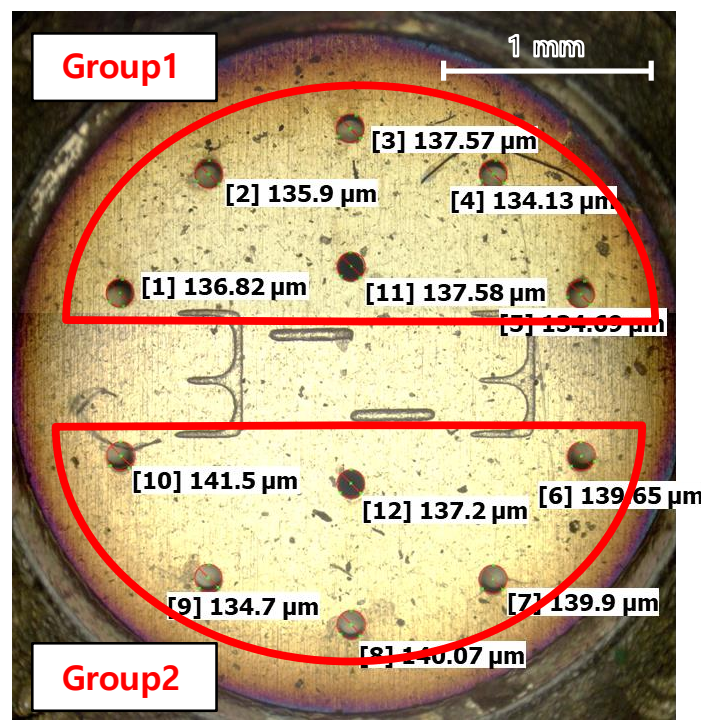

(c)

Figure 3. Specifications of PFI system used in experiment: (a) Schematic diagram of 12-hole PFI system, (b) measured each hole diameter, (c) close-up photograph of orifice using SEM.

\section{Results and Discussion}

Figure 4 is a graph comparing the injection quantity of water and n-heptane according to the change between injection pressure and energizing duration. The injection pressure was changed to $0.3 \mathrm{MPa}, 0.5 \mathrm{MPa}, 0.7 \mathrm{MPa}$, and $0.9 \mathrm{MPa}$ and the energizing duration was changed from $0.5 \mathrm{~ms}$ to $4.0 \mathrm{~ms}$ in $0.5 \mathrm{~ms}$ units. As shown in Figure 4, the injection quantity of water and n-heptane increased with increasing injection pressure and energizing duration. In addition, the injection quantity of water was about $21 \%$ higher than that of n-heptane. This is because the density of water is larger than that of n-heptane. In general, the injection flow rate of the fluid was proportional to the density when the flow cross section and the velocity (or differential pressure) were constant.

$$
\dot{m}=\rho A \bar{V}
$$

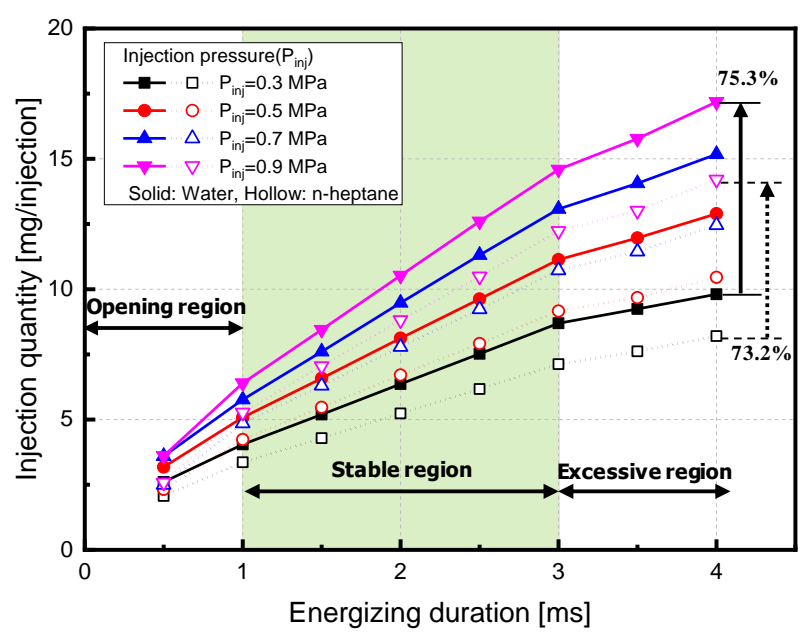

Figure 4. Comparison of the injection quantity between water and n-heptane for the injection pressure and energizing duration. 
The density of water is about 1.47 times higher than that of n-heptane. However, since the surface tension of water is 3.51-times higher than that of n-heptane, the difference in injection quantity $(21 \%)$ is considered to be smaller than the density difference (47\%) due to drag caused by surface tension. When the injection pressure was increased from $0.3 \mathrm{MPa}$ to $0.9 \mathrm{MPa}$, the injection quantity of water and n-heptane increased to $75.3 \%$ and $73.2 \%$, respectively (with a duration of $4.0 \mathrm{~ms}$ ), regardless of the type of fuel. The injection quantity tended to increase in proportion to the injection pressure $(\sqrt{\Delta P})$. On the other hand, it can be seen that the increase rate of injection quantity decreases when the energizing duration is $1.0 \mathrm{~ms}$ and $3.0 \mathrm{~ms}$ at all injection pressures. Based on this, the injection quantity graph can be divided into three regions. Based on this branching point ( $\mathrm{t}_{\mathrm{eng}}=1 \mathrm{~ms}$ and $3 \mathrm{~ms}$ ), regions were divided into three sections: The opening region $(\sim 1.0 \mathrm{~ms})$, stable region $(1.0 \mathrm{~ms} \sim 3.0 \mathrm{~ms})$, and excessive region $(3.0 \mathrm{~ms} \sim)$. In the opening region before $1.0 \mathrm{~ms}$, the injection was terminated before the injector needle was completely lifted due to an insufficient energizing duration, which resulted in unstable flow characteristics such as smaller flow rate than other areas and unclear flow characteristics due to change in injection pressure. In the stable region $(1 \mathrm{~ms} \sim 3.0 \mathrm{~ms})$, the needle was lifted to the highest height and spray was stable. The spray quantity increased linearly with increasing energizing duration at each injection pressure. In the region after $3.0 \mathrm{~s}$ (excessive region), the injection quantity increased linearly with energizing duration. The increase rate was slightly lower than the stable region. The injector used in this study was confirmed to be a stable injection area at $t_{\text {eng }}=1-3 \mathrm{~ms}$. Therefore, $2.795 \mathrm{~ms}$ was set as the representative energizing duration in terms of spray behavior and droplet size measurement.

Figure 5 shows spray development of water and n-heptane over time after the start of injection. The raw image of the spray was expressed in color according to light intensity. The closer to red, the more spray droplets existed, which means that the light reflection was large. In particular, the more droplets of fuel and the wider droplets of fuel, the greater the light intensity. Therefore, Figure 5 can be used as an indicator to relatively determine the degree of spray dispersion and atomization. As shown in Figure 5, n-heptane had excellent atomization characteristics with lower surface tension and viscosity than water. The brightness of the image was high due to the spread of spray and the scattering of light. On the other hand, since water is not easily atomized (especially at low injection pressure conditions), light scattering did not occur well. Thus, the form of spray appeared faint. When the injection pressure was increased, the breakup and atomization of both fuels proceeded well and the light intensity increased due to the increased number of droplets. This result showed that when water is injected at a low pressure, the atomization of the sprayed water is not smooth [28]. It is sprayed in the form of a liquid column to reach the intake port wall surface. Thus, the wall-wetting phenomenon is likely to occur. To prevent the wall-wetting phenomenon, water requires a higher injection pressure than $\mathrm{n}$-heptane. In addition, $\mathrm{n}$-heptane had a high light intensity throughout the whole spray plume, whereas water had a high light intensity at the end of the spray plume. The results of quantitative analysis of the spray development of water and n-heptane are shown in Figures 6 and 7.

Figure 6 shows spray tip penetration characteristics of water and n-heptane according to the change of injection pressure and current. Under the same spray conditions, spray tip penetration of n-heptane was $11.2-17.6 \%$ longer than that of water. Despite the high density of water, the spray tip penetration of water was shorter than that of n-heptane due to the high surface tension and viscosity. As shown in 'Region A' of Figure 6a, the development of spray was unstable at the initial stage of spray (about $0.5 \mathrm{~ms}$ after spraying). Therefore, it was difficult to confirm the clear difference in spray tip penetration according to injection pressure and test fuel. Under all test conditions, the spray tip penetration increased linearly with time after start of injection. The increase in injection pressure affected the initial velocity increase of the spray, leading to an increase in spray tip penetration (according to Bernoulli's equation, the velocity was proportional to $\sqrt{\Delta P}$ ). As the injection pressure increased from $0.3 \mathrm{MPa}$ to $0.9 \mathrm{MPa}$, water increased up to $31.7 \%$ and n-heptane increased up to $22.5 \%$. In Figure $6 b$, however, the change of the energizing duration did not significantly affect the spray tip penetration of $\mathrm{n}$-heptane or water. This is because the change of energizing duration under the same injection pressure (differential pressure) condition does not affect the velocity of initial droplets. 


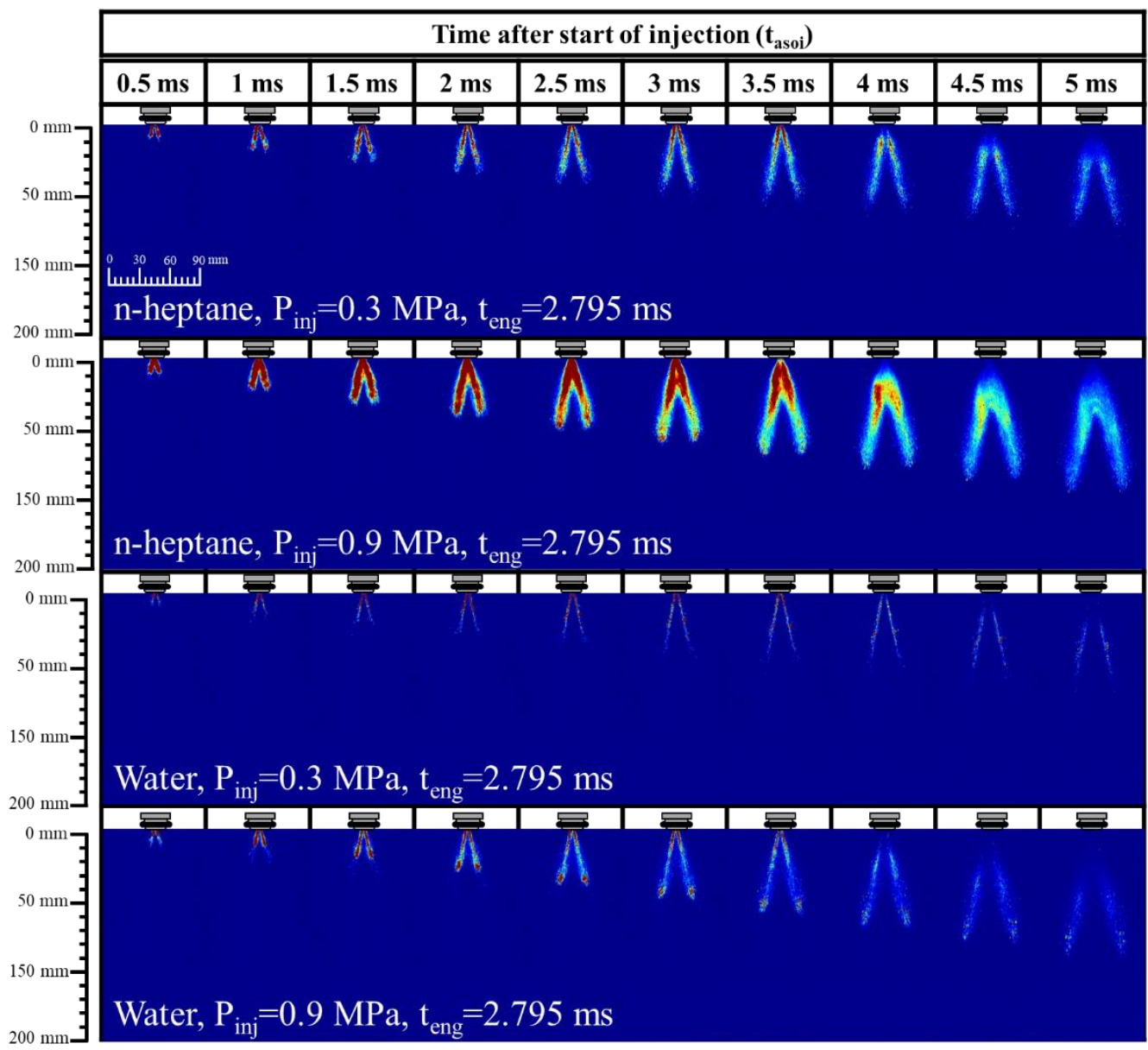

Figure 5. Spray developing process of water and n-heptane according to the time after start of injection $\left(\mathrm{P}_{\text {inj }}=0.3 \mathrm{MPa}\right.$ and $\left.0.9 \mathrm{MPa}, \mathrm{P}_{\mathrm{amb}}=0.1 \mathrm{MPa}, \mathrm{t}_{\mathrm{eng}}=2.795 \mathrm{~ms}\right)$.

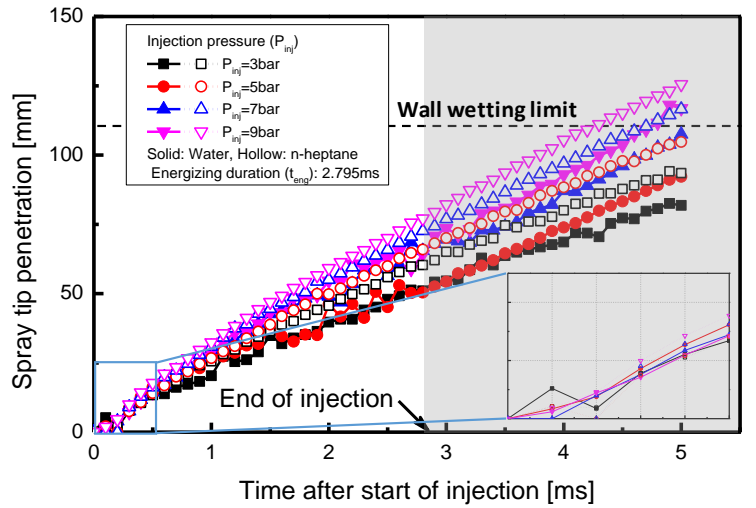

(a)

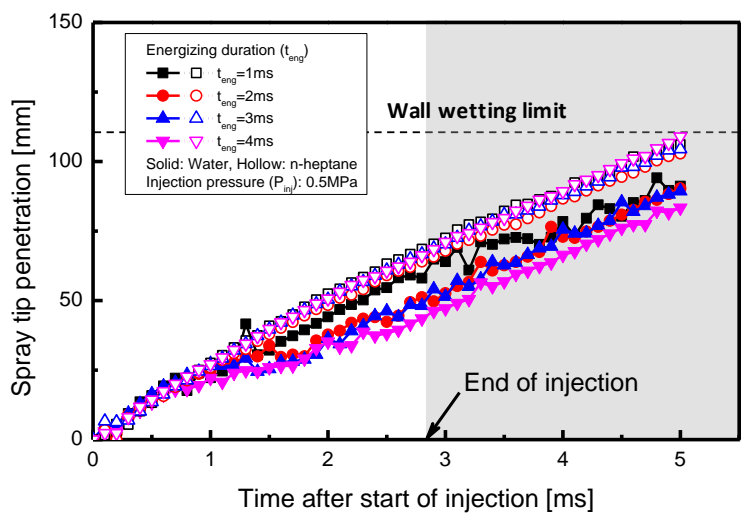

(b)

Figure 6. Spray tip penetration characteristics for (a) injection pressure and (b) energizing duration.

Figure 8 shows a schematic diagram of installing PFI systems used in this study on the design engine. The distance from the nozzle tip to the intake valve wall of the design engine was about $120 \mathrm{~mm}$. For this reason, it can be seen that when installing the injector in the intake port for water injection, the STP should not exceed $120 \mathrm{~mm}$ more than needed. This is defined as a wall wetting limit and is shown in the graph. When water was injected, the STP increased. However, it was confirmed that the wall wetting limit was not reached under most conditions. Therefore, it is expected that water will not generate a direct wall wetting phenomenon, even at higher injection pressure. From these 
results, it can be seen that spray tip penetration control of water injection to the design distance of each engine is essential for water injection.

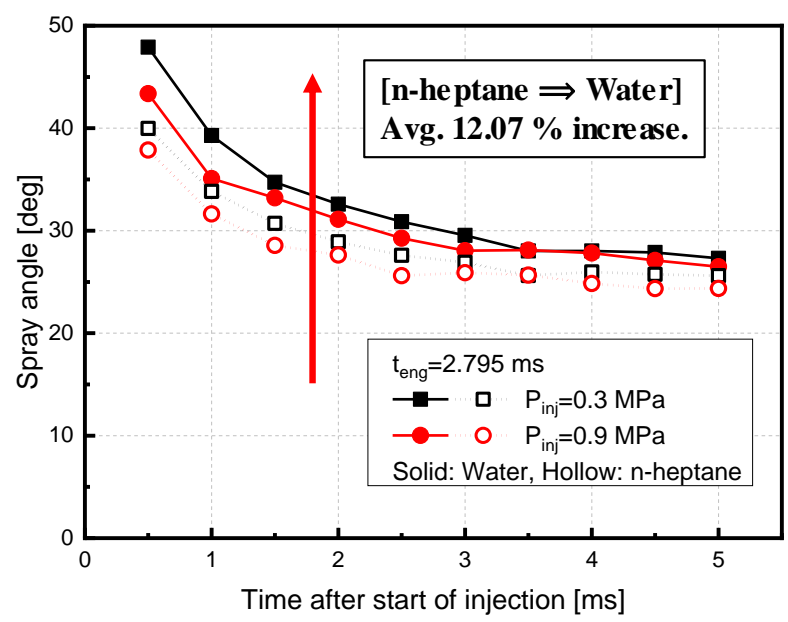

Figure 7. Spray angle characteristics of water and n-heptane according to time after start of injection $\left(\mathrm{t}_{\text {eng }}=2.795 \mathrm{~ms}\right)$.

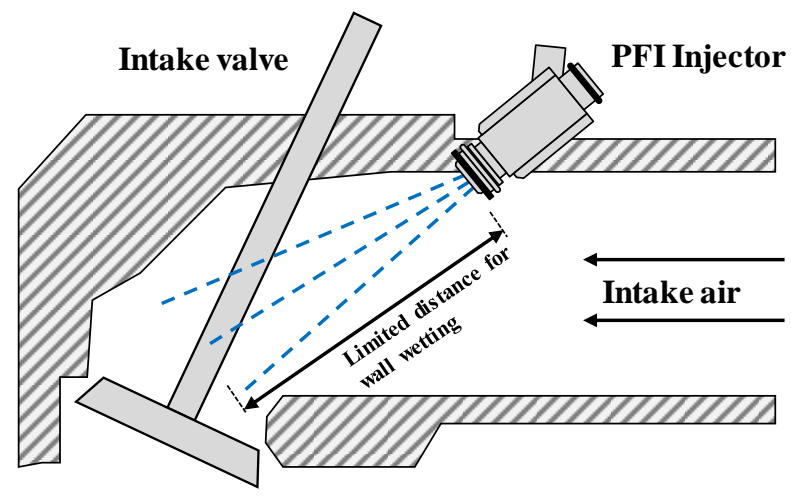

Figure 8. Schematic diagram of intake port in PFI system and definition of limited distance for wall wetting.

Spray cone angles of water and n-heptane according to spray pressure are shown in Figure 7. As shown in the figure, both fuels showed a high initial injection cone angle which decreased over time. Although the injection cone angle of the injector used in this study was designed to be $20^{\circ}$, the initial injection cone angle was determined to be high because the distance from the injector tip to the spray edge was too close. Over time, the spray cone angle gradually decreased to approximate $20^{\circ}$ and the rate of decrease of the spray cone angle decreased. At high injection pressures, the injection cone angle was low and the injection cone angle decreased up to $10.7 \%$ for water and $7.2 \%$ for $n$-heptane with increasing injection pressure from 0.3 MPa to $0.9 \mathrm{MPa}$. This was because the linearity of the injected fluid increased with increasing injection pressure, while the radial velocity decreased. On the other hand, the injection cone angle of water was $12.07 \%$ larger than that of n-heptane. This was because the viscosity and surface tension of the water were relatively large, making it difficult for water to be atomized (see Figure 5). The spray tip penetration was short and developed in the radial direction. In addition, a large injection quantity of water sprayed under the same spray conditions also caused an increase in the spray angle.

Figures 9-11 compare atomization properties of water and n-heptane. These atomization characteristics were explained using spray droplet size, distribution, and droplet velocity. The size of spray droplets can serve as a measure of atomization degree of the spray. The finer the atomization, the better the mixture. Figure 10 compares the SMDs of n-heptane and water according to the change 
of injection pressure at the point where the distance from the nozzle tip to the measurement section was $30 \mathrm{~mm}$ and $60 \mathrm{~mm}$, respectively. As shown in Figure 9a,b, SMDs of water and n-heptane decreased as injection pressure increased. This was because aerodynamic splitting actively progressed with increasing relative velocity between the fluid and ambient air due to an increase in injection pressure. When the injection pressure increased from 0.3 MPa to 0.9 MPa, the SMD decreased $87.8 \%$ in water and $47.1 \%$ in $n$-heptane. The SMD of water was measured greater than that of $n$-heptane at an average of $74.5 \%$ at $30 \mathrm{~mm}$ from the nozzle tip and $56.5 \%$ at $60 \mathrm{~mm}$. It has been confirmed that SMD is a dominant function of We (weber number), that is, the surface tension of water is twice as high as n-heptane and the droplet size at the center of the injector is up to about two times greater. In addition, the difference of SMD between water and $n$-heptane increased as the injection pressure increased. Water increased SMD toward the center of the injector, whereas n-heptane decreased SMD at the center of the injector. It can be seen that droplets of water with high surface tension were coalesced, while the droplets of $\mathrm{n}$-heptane with low surface tension were broken up in the process of droplets injected from six holes collided with each other.

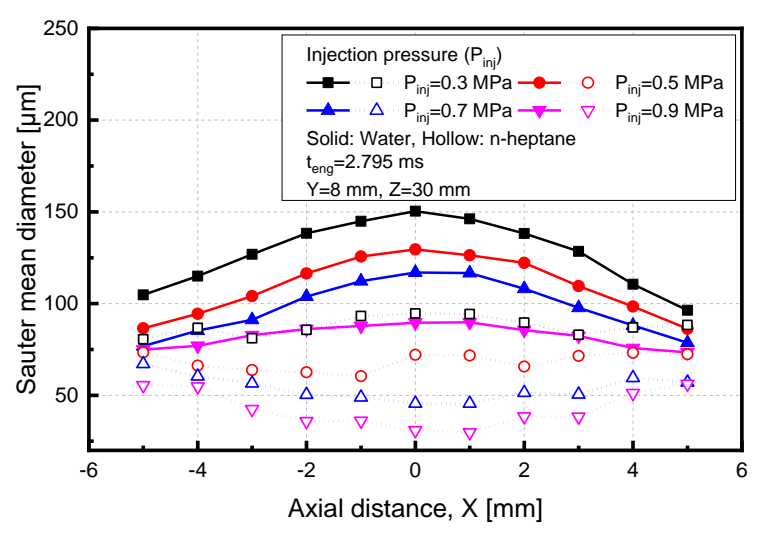

(a)

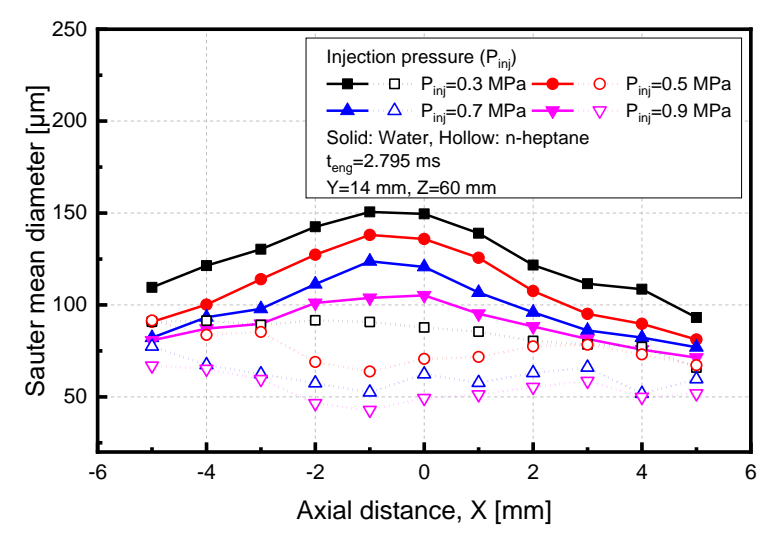

(b)

Figure 9. Average size characteristics of water and n-heptane under different injection pressure at (a) $D_{\text {tip }}=30 \mathrm{~mm},(\mathbf{b}) \mathrm{D}_{\text {tip }}=60 \mathrm{~mm}$.

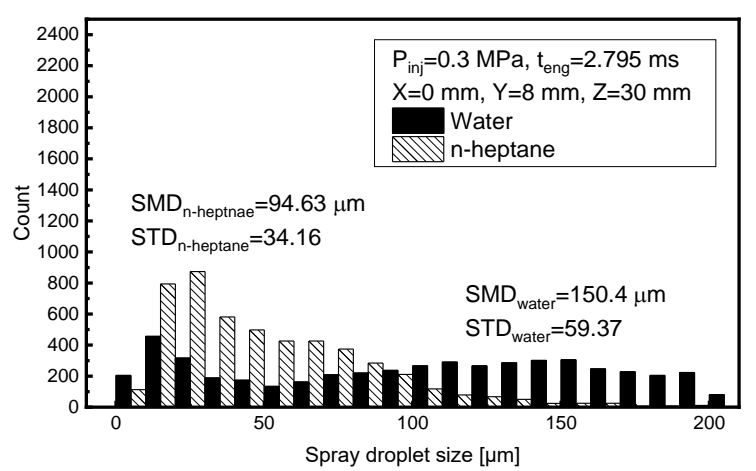

(a)

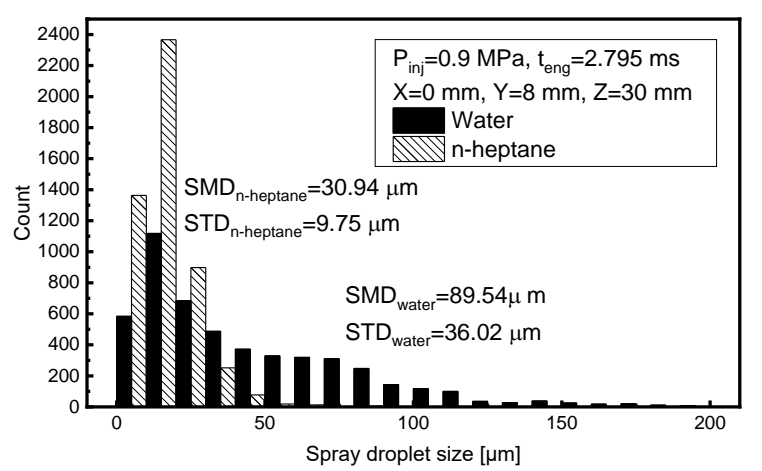

(b)

Figure 10. Droplet size distribution of water and n-heptane under two injection pressure at (a) $P_{\text {inj }}=0.3 \mathrm{MPa}$, (b) $\mathrm{P}_{\text {inj }}=0.3 \mathrm{MPa}\left(\mathrm{t}_{\text {eng }}=2.795 \mathrm{~ms}, \mathrm{X}=0 \mathrm{~mm}, \mathrm{Y}=8 \mathrm{~mm}, \mathrm{Z}=30 \mathrm{~mm}\right.$ ).

Figure 10 compares droplet size distribution of water and n-heptane. For each experimental condition, data for a total of 5000 droplets were obtained. Comparison of the droplet size distribution was performed at points $X=0 \mathrm{~mm}, Y=8 \mathrm{~mm}$, and $30 \mathrm{~mm}$ away from the nozzle tip $(\mathrm{Z}=30 \mathrm{~mm})$. It could be seen that the shape of distribution of water and n-heptane was significantly different at injection pressure of 0.3 MPa. As shown in Figure 10a, when n-heptane was injected, there were many small droplets. The larger the size, the smaller the number. On the other hand, water droplets 
were relatively even distributed in size. The number of large droplets for water was larger than that for n-heptane. This caused the SMD of water to appear larger than that of n-heptane. In addition, the standard deviation was $34.16 \mu \mathrm{m}$ for n-heptane and $59.371 \mu \mathrm{m}$ for water. In the process of water droplets continuously colliding with each other, it is judged that the distribution of droplet size was relatively even because the collision and coalescence of droplets were repeated due to the high surface tension of water.

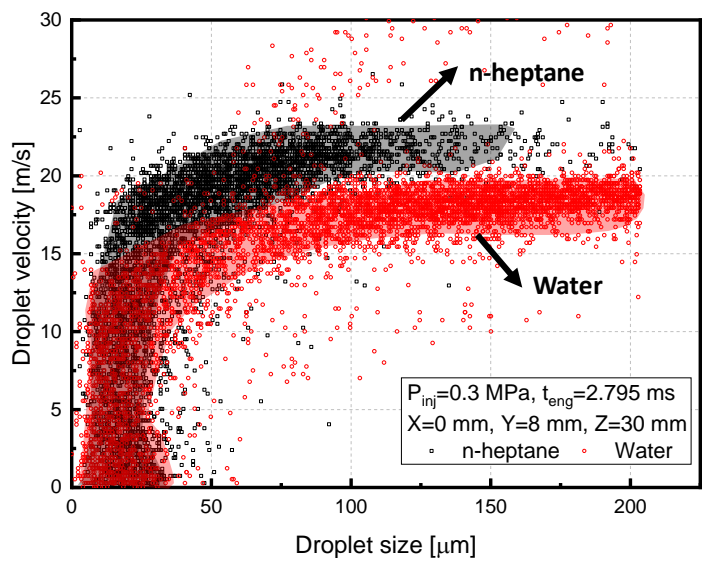

(a)

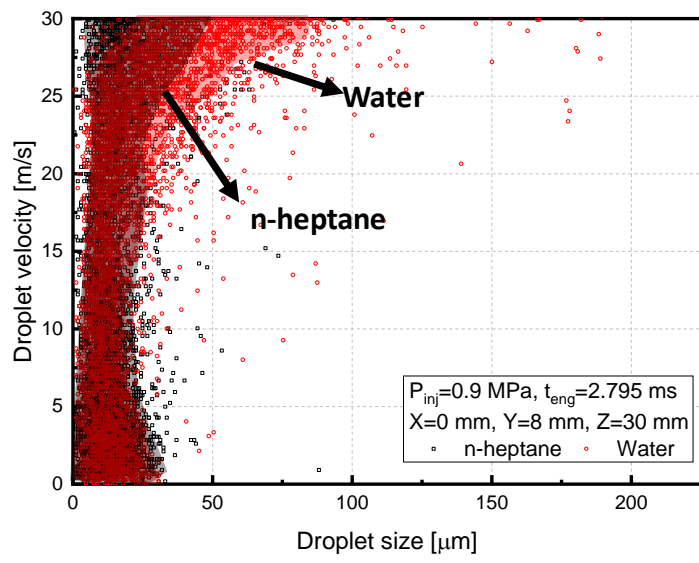

(b)

Figure 11. Comparison of distribution correlation of droplet velocity and size of water and n-heptane at (a) $P_{\text {inj }}=0.3 \mathrm{MPa}$, (b) $P_{\text {inj }}=0.9 \mathrm{MPa}$.

However, as shown in Figure 10b, droplets developed with high momentum due to the high injection pressure, overcoming the surface tension of water and breaking up actively. Therefore, like n-heptane, water was observed to have relatively small size distribution at a low injection pressure. However, at high injection pressure $(0.9 \mathrm{MPa})$, n-heptane also exhibited a smaller SMD than water, as its breakup was more active, and the number of smaller droplets was increased. That is, water always had a larger SMD than n-heptane due to its high viscosity and surface tension. In the results shown in Figure 10a,b, when water was injected at a pressure of $0.9 \mathrm{MPa}$, it had similar atomization characteristics to those of $\mathrm{n}$-heptane injected at $0.3 \mathrm{MPa}$. Therefore, when water is injected into the intake port, the injection pressure should be increased for smooth mixing with the intake air through the active breakup activity. As the injection pressure increased from $0.3 \mathrm{MPa}$ to $0.9 \mathrm{MPa}$, the SMD of n-heptane decreased by $67.3 \%$ and, while the SMD of water decreased by $40.47 \%$.

Figure 11 shows the distribution of SMD-Velocity with variation of injection pressure at $t_{\text {eng }}=2.795 \mathrm{~ms}$ of $\mathrm{n}$-heptane and water using PFI systems. The velocity and size of each of 5000 droplets are shown in the distribution graph. Figure 11a shows the SMD-Velocity distribution at an injection pressure of $0.3 \mathrm{MPa}$. It can be seen that droplets of n-heptane were distributed in a smaller size area than those of water. When the injection pressure was increased, most droplets were concentrated in the small size area of spray droplets. When the injection pressure increased, the injection speed also increased. In addition, when the injection pressure increased, the initial spray momentum increased, as well as the injection velocity. Figure $11 \mathrm{~b}$ shows SMD-Velocity distribution at an injection pressure of $0.9 \mathrm{MPa}$. At the same pressure, water was spread evenly to the region of larger droplet size distribution than n-heptane. Thus, the velocity of water droplets was lower than that of $n$-heptane. As with n-heptane, water was found to decrease the spray droplet size, concentrate the distribution of droplets size, and increase the spray droplet velocity as injection pressure increased.

\section{Conclusions}

In this study, the injection and spray characteristics of water injection for a 12-hole PFI system were compared experimentally with those of n-heptane. We performed the following experiments under 
various injection conditions: Injection quantity measurement, STP and spray cone angle measurement using mie-scattering, and measurement of spray droplet size and velocity using a PDA. The effects of water injection were analyzed using this method and new requirements for applying water injection were proposed. The main results of this paper are summarized below.

1. Due to the high density of water, the injection quantity of water increased $21 \%$ compared to $\mathrm{n}$-heptane. Therefore, spray control is easier because the energizing duration of water is shorter compared to that of $\mathrm{n}$-heptane for injecting the same injection quantity.

2. In comparison with n-heptane, water spray tip penetration decreased and spray angle increased slightly. When water is injected, it is advantageous for wall wetting due to its shorter STP compared to $\mathrm{n}$-heptane. On the other hand, the injection cone angle will not affect wall wetting because the increase in injection cone angle is very small.

3. Due to characteristics of the PFI system operating at low pressure, the water breakup was not good. As a result, the SMD was larger than n-heptane and the spray droplet velocity was decreased. It was confirmed that injection conditions for stable water supply and accurate spray targeting should be applied due to injection and spray characteristics that vary by water injection instead of fuel injection at PFI systems. To reduce the droplet size of sprayed water and concentrate the spray droplet size distribution, it is necessary to increase the injection pressure and further study combustion characteristics according to the water and air mixture characteristics.

Author Contributions: All authors contributed to the experiments, analysis, and the deployment of the paper. Spray experiment and data analysis, J.P.; Result analysis, developing the research method, and setup of research topic, K.-H.L.; Experimental design, data analysis, summarizing and correspondence of the paper, S.P. Authorship must be limited to those who have contributed substantially to the work reported. All authors have read and agree to the published version of the manuscript.

Funding: This work was supported by the National Research Foundation of Kora (NRF) grant funded by the Korea government (MSIT) (No. 2019R1A2C1089494). Also, this research was supported by the CEFV (Center for Environmentally Friendly Vehicle) as Global-Top Project of KMOE (Ministry of Environment, Korea) (No. 2019002070001).

Conflicts of Interest: The authors declare no conflict of interest. The funders had no role in the design of the study; in the collection, analyses, or interpretation of data; in the writing of the manuscript, or in the decision to publish the results.

\section{References}

1. Gerty, M.D.; Heywood, J.B. An Investigation of Gasoline Engine Knock Limited Performance and the Effects of Hydrogen Enhancement; SAE Technical Paper; SAE International: Warrendale, PA, USA, 2006; ISSN $0148-7191$.

2. Pauer, T.; Frohnmaier, M.; Walther, J.; Schenk, P.; Hettinger, A.; Kampmann, S. Optimization of gasoline engines by water injection. In Proceedings of the 37th International Vienna Motor Symposium, Vienna, Austria, 28-29 April 2016.

3. Rohit, A.; Satpathy, S.; Choi, J.; Hoard, J.; Surnilla, G.; Hakeem, M. Literature Survey of Water Injection Benefits on Boosted Spark Ignited Engines; SAE Technical Paper; SAE International: Warrendale, PA, USA, 2017; ISSN 0148-7191.

4. Zhu, S.; Hu, B.; Akehurst, S.; Copeland, C.; Lewis, A.; Yuan, H.; Kennedy, I.; Bernards, J.; Branney, C. A review of water injection applied on the internal combustion engine. Energy Convers. Manag. 2019, 184, 139-158. [CrossRef]

5. Zhen, X.; Wang, Y.; Xu, S.; Zhu, Y.; Tao, C.; Xu, T.; Song, M. The engine knock analysis-an overview. Appl. Energy 2012, 92, 628-636. [CrossRef]

6. Hoppe, F.; Thewes, M.; Baumgarten, H.; Dohmen, J. Water injection for gasoline engines: Potentials, challenges, and solutions. Int. J. Engine Res. 2016, 17, 86-96. [CrossRef]

7. Berni, F.; Breda, S.; Lugli, M.; Cantore, G. A numerical investigation on the potentials of water injection to increase knock resistance and reduce fuel consumption in highly downsized GDI engines. Energy Procedia 2015, 81, 826-835. [CrossRef]

8. Tsao, K.; Wang, C.; Miller, E. Performance of Gasoline-Water Fuel in a Modified Si Engine; SAE Technical Paper; SAE International: Warrendale, PA, USA, 1984; ISSN 0148-7191. 
9. Russ, S. A Review of the Effect of Engine Operating Conditions on Borderline Knock; SAE Technical Paper; SAE International: Warrendale, PA, USA, 1996; ISSN 0148-7191.

10. Caris, D.; Nelson, E. A new look at high compression engines. In SAE Transactions; SAE International: Warrendale, PA, USA, 1959; pp. 112-124.

11. Lestz, S.S.; Meyer, W.E.; Colony, C. Emissions from a Direct-Cylinder Water-Injected Spark-Ignition Engine; SAE Technical Paper; SAE International: Warrendale, PA, USA, 1972; ISSN 0148-7191.

12. Lanzafame, R. Water Injection Effects in a Single-Cylinder CFR Engine; SAE Technical Paper; SAE International: Warrendale, PA, USA, 1999; ISSN 0148-7191.

13. Fu, L.; Wu, Z.; Yu, X.; Deng, J.; Hu, Z.; Li, L. Experimental investigation of combustion and emission characteristics for internal combustion rankine cycle engine under different water injection laws. Energy Proced. 2015, 66, 89-92. [CrossRef]

14. Eaton, D. Cruising Economy by Use of Water Injection; SAE Technical Paper; SAE International: Warrendale, PA, USA, 1946; ISSN 0148-7191.

15. Rowe, M.; Ladd, G. Water Injection for Aircraft Engines; SAE Technical Paper; SAE International: Warrendale, PA, USA, 1946; ISSN 0148-7191.

16. Worm, J.; Naber, J.; Duncan, J.; Barros, S.; Atkinson, W. Water injection as an enabler for increased efficiency at high-load in a direct injected, boosted, SI engine. SAE Int. J. Engines 2017, 10, 951-958. [CrossRef]

17. Sun, Y.; Fischer, M.; Bradford, M.; Kotrba, A.; Randolph, E. Water Recovery from Gasoline Engine Exhaust for Water Injection; SAE Technical Paper; SAE International: Warrendale, PA, USA, 2018; ISSN 0148-7191.

18. Younkins, M.; Wooldridge, M.S.; Boyer, B.A. Port Injection of Water into a Di Hydrogen Engine; SAE Technical Paper; SAE International: Warrendale, PA, USA, 2015; ISSN 0148-7191.

19. Hountalas, D.T.; Mavropoulos, G.C.; Zannis, T.; Mamalis, S. Use of Water Emulsion and Intake Water Injection as Nox Reduction Techniques for Heavy Duty Diesel Engines; SAE Technical Paper; SAE International: Warrendale, PA, USA, 2006; ISSN 0148-7191.

20. Tornatore, C.; Siano, D.; Marchitto, L.; Iacobacci, A.; Valentino, G.; Bozza, F. Water injection: A technology to improve performance and emissions of downsized turbocharged spark ignited engines. SAE Int. J. Engines 2017, 10, 2319-2329. [CrossRef]

21. Bellato, N.; Alegre, G.; Di Meo, A.; Moura, T.; Windlin, F.; Montanari, G. Numerical and Experimental Methodologies to Predict Characteristics of BioFuel Blend on PFI Injector; SAE Technical Paper; SAE International: Warrendale, PA, USA, 2012; ISSN 0148-7191.

22. Anand, T.; Mohan, A.M.; Ravikrishna, R. Spray characterization of gasoline-ethanol blends from a multi-hole port fuel injector. Fuel 2012, 102, 613-623. [CrossRef]

23. Zhu, R.; Hu, J.; Bao, X.; He, L.; Lai, Y.; Zu, L.; Li, Y.; Su, S. Tailpipe emissions from gasoline direct injection (GDI) and port fuel injection (PFI) vehicles at both low and high ambient temperatures. Environ. Pollut. 2016, 216, 223-234. [CrossRef] [PubMed]

24. Bhagat, M.; Cung, K.; Johnson, J.; Lee, S.-Y.; Naber, J.; Barros, S. Experimental and Numerical Study of Water Spray Injection at Engine-Relevant Conditions; SAE Technical Paper; SAE International: Warrendale, PA, USA, 2013; ISSN 0148-7191.

25. Hoppe, F.; Thewes, M.; Seibel, J.; Balazs, A.; Scharf, J. Evaluation of the potential of water injection for gasoline engines. SAE Int. J. Engines 2017, 10, 2500-2512. [CrossRef]

26. Lefebvre, A.H.; McDonell, V.G. Atomization and Sprays; CRC Press: Boca Raton, FL, USA, 2017.

27. Dos Santos, F.; Le Moyne, L. Spray atomization models in engine applications, from correlations to direct numerical simulations. Oil Gas. Sci. Tech. Rev. D'IFP Energies Nouv. 2011, 66, 801-822. [CrossRef]

28. Hiroyasu, H.; Arai, M. Structures of Fuel Sprays in Diesel Engines. In SAE Transactions; SAE International: Warrendale, PA, USA, 1990; pp. 1050-1061.

(C) 2020 by the authors. Licensee MDPI, Basel, Switzerland. This article is an open access article distributed under the terms and conditions of the Creative Commons Attribution (CC BY) license (http://creativecommons.org/licenses/by/4.0/). 